\title{
Article
}

\section{Enhanced anti-psoriatic efficacy and regulation of oxidative stress of a novel topical babchi ofl (Psoralea corylifolia) cyclodextrin-based nanogel in a mouse tail model}

Kumar, Sunil, Singh, Kamalinder and Rao, Rekha

Available at http://clok.uclan.ac.uk/28448/

Kumar, Sunil, Singh, Kamalinder ORCID: 0000-0001-7325-0711 and Rao, Rekha (2019) Enhanced anti-psoriatic efficacy and regulation of oxidative stress of a novel topical babchi oil (Psoralea corylifolia) cyclodextrin-based nanogel in a mouse tail model. Journal of Microencapsulation, 36 (2). pp. 140155. ISSN 0265-2048

It is advisable to refer to the publisher's version if you intend to cite from the work. http://dx.doi.org/10.1080/02652048.2019.1612475

For more information about UCLan's research in this area go to

http://www.uclan.ac.uk/researchgroups/ and search for < name of research Group>.

For information about Research generally at UCLan please go to http://www.uclan.ac.uk/research/

All outputs in CLoK are protected by Intellectual Property Rights law, including Copyright law. Copyright, IPR and Moral Rights for the works on this site are retained by the individual authors and/or other copyright owners. Terms and conditions for use of this material are defined in the policies page. 


\title{
Enhanced anti-psoriatic efficacy and regulation of oxidative stress of a novel topical babchi oil (Psoralea corylifolia) cyclodextrin-based nanogel in a mouse tail model
}

\author{
Sunil Kumar, Kamalinder K Singh \& Rekha Rao
}

To cite this article: Sunil Kumar, Kamalinder K Singh \& Rekha Rao (2019): Enhanced antipsoriatic efficacy and regulation of oxidative stress of a novel topical babchi oil (Psoralea corylifolia) cyclodextrin-based nanogel in a mouse tail model, Journal of Microencapsulation, DOI: 10.1080/02652048.2019.1612475

To link to this article: https://doi.org/10.1080/02652048.2019.1612475

Accepted author version posted online: 27

Apr 2019.

Submit your article to this journal $2 \pi$

Џ Article views: 5

View Crossmark data $־$ 


\title{
Enhanced anti-psoriatic efficacy and regulation of oxidative stress of a novel topical babchi oil (Psoralea corylifolia) cyclodextrin-based nanogel in a mouse tail model
}

\author{
Sunil Kumar ${ }^{\mathrm{a}}$, Kamalinder K Singh ${ }^{\mathrm{b}}$, Rekha $\operatorname{Rao}^{\mathrm{a}^{*}}$ \\ ${ }^{a}$ Department of Pharmaceutical Sciences, Guru Jambheshwar University of Science and \\ Technology, Hisar-125001, Haryana, India. \\ ${ }^{\mathrm{b}}$ School of Pharmacy and Biomedical Sciences, University of Central Lancashire, Preston, \\ Lancashire, PR1 2HE, England.
}

*Email: rekhaline@gmail.com

Abstract:

Psoriasis is a proliferative inflammatory skin disorder with relapsing episodes. Herein, the efficacy of babchi oil (BO) loaded nanostructure gel was evaluated for antipsoriatic activity and oxidative stress biomarkers assessment using mouse tail model. BO was entrapped into cyclodextrin-based nanocarriers $(360.9 \pm 19.55 \mathrm{~nm})$, followed by incorporation into a Carbopol gel and characterized for viscosity, spreadability and texture analysis. The gels were topically applied on mouse-tails once daily for fourteen days. Evaluation of antipsoriatic activity as determined by histopahological observations of orthokeratotic epidermis revealed two times higher efficacy of BO nanogel than the native BO gel. Further, significantly enhanced superoxide dismutase (SOD) and reduced glutathione (GSH) levels and diminished malondialdehyde (MDA) and nitrite (NO) levels revealed that nanogels played a major role in management of ROS associated in psoriasis pathogenesis. Hence, this study provides strong evidence for use cyclodextrin-based nanogels as safe and better delivery carrier of BO for management of psoriasis.

Keywords: Cyclodextin-based nanostructures; babchi oil; carbopol gel; mouse-tail model; lipid peroxidation; antioxidant enzymes.

\section{Introduction}

Psoriasis is one of the recurrent and chronic inflammatory disorder native to painful, scaly, itchy skin resulting in disfiguring lesions. More than 125 million people are estimated to be suffering from this disease worldwide [Langan et al., 2012, World Health Organization. Global report on psoriasis, 2016]. The impact of skin diseases such as psoriasis is generally underestimated since "a person hardly ever dies from a skin disease" but these can be very troublesome and has significant psychosocial embarrassment and cause deterioration in patient's quality of life. 
Psoriasis manifests itself by hyperproliferation and altered differentiation of keratinocytes [Suresh et al., 2013]. It is associated with various immunological and biochemical disturbances and involves multitude of coherent events including activation of circulating immune cells along with their secreted signalling molecules like chemokines, cytokines and growth factors resulting in congealing of epidermis, hyperkeratosis and neovascularisation [Pradhan et al., 2013].

Since the pathogenesis of psoriasis includes a complex series of molecular phenomena, various treatment strategies involving topical, systemic and phototherapy have been employed for its management [Paul et al., 2011]. Scientific information supports that topical therapy is still the mainstay for approximately $70 \%$ of patients, while remaining $30 \%$ condition is largely managed with systemic pharmacotherapy [Carrascosa et al., 2006]. Also, topical mode very often remains compliment part of the systemic treatment regimen. Topical medications for psoriasis include corticosteroids, topical retinoids, athralin, calcineurin inhibitors etc. However, these synthetic drugs have their own limitations [Carrascosa et al., 2006, Menter et al., 2007, Paul et al., 2011]. Therefore, there is imperative need of alternative safer and effective treatments for psoriasis.

There has been renewed interest in natural products based research due to failure of alternative drug discovery techniques in delivering therapeutic moieties [Lahlou, 2013]. Essential oils are complex compounds present in aromatic plants as secondary metabolites and possess two or more bioactives in relatively higher concentrations (20-70\%) [Bakkali et al., 2008]. One such essential oil, babchi oil provides alternative treatment for psoriasis with least side effects as compared to the synthetic drugs recommended for this disease [Marwaha and Bhise, 2014, Kumar and Rao, 2016, Raut and Wairkar, 2018]. In Ayurveda and traditional Chinese medicine, babchi oil has been suggested for treatment of skin diseases due to its anti-microbial, antioxidant and anti-inflammatory properties [Chopra et al., 2013]. Obtained from Psoralea corylifolia seeds (family leguminoseae), this essential oil is a phytotherapeutic agent with furocoumarins as major constituents that restrain DNA synthesis and cause retardation of cell proliferation, resulting in anti-psoriatic action [Khushboo et al., 2010]. Although, there are several ayurvedic formulations of babchi oil in Indian market, however, psoralen has not been assessed from traditional commercial preparations. In addition, pharmacokinetics of any traditional preparation has not been reported in literature using psoralen [Shailajan et al., 2012]. Besides this, BO suffers from instabilities resulting from oxygen, temperature and light that can lead to its oxidation and degradation. Further, skin irritation and toxicity of babchi oil are other issues needed to be handled. These shortcomings limit its practical use of BO inspite of its promising antipsoriatic potential. In previous reports, limited BO-based formulations have been reported, encompassing nanostructure lipid carriers and microsponges [Faiyazuddin et al., 2010, Wadhwa et al., 2019].

The use of colloidal drug carriers is of great interest for skin delivery of therapeutic agents [Pople and Singh, 2011]. Not only they improve penetration of drugs into the skin but also allow their extended drug release and reduce skin-irritating effect of the topical agents [Pople and Singh, 2013, Robert et al., 2017]. There is an increased interest in scientific community for delivering phytocompounds as nanocarriers, which has emerged as a potential alternative 
strategy for management of skin disorders [Sampada and Singh, 2015, Falcão et al., 2018]. There is no marketed novel formulation of the babchi oil that overcomes the above mentioned problems of the BO. Encapsulation of essential oils in nanocarriers including nanostructured lipid carriers [Nahr et al., 2018], liposomes [Low et al., 2013, polymeric nanoparticles [Dima et al., 2014], niosomes [Leelarungrayub et al., 2017], solid lipid nanoparticles [Moghimipour et al., 2013] has been employed to improve their stability as well as efficacy [El Asbahani et al., 2015]. Cyclodextrin based nanostructures are novel multifunctional nanoskilled systems composed of biocompatible cross-linked polymers. These are highly porous nanostructures with 3-dimensional rings and nanometric cavities with unique capacity to entrap active molecules offering the benefit of programmable release [Trotta et al., 2012]. These can be explored as a novel approach to stabilize essential oils and increase their efficacy [Aldawsari et al., 2015, Bachir et al., 2017]. Nanostructures have also shown remarkably improved drug permeation of a phytoconstituent in in vitro assays carried out using porcine skin [Ansari et al., 2011, Sapino et al., 2013]. Additionally, cyclodextrins have been well established in literature to alleviate local irritancy and promote drug transport, which is particularly important attribute in treating psoriasis [Wadhwa et al., 2017] as the skin in this disorder (being rough and ingrained with plaques) impose as major barrier in topical delivery of drugs [Pradhan et al., 2013]. In our previous work, we developed babchi oil loaded nanosponges which were partially characterized in regard of cytotoxicity, photostability and antimicrobial studies [Kumar et al., 2018]. However, it is essential for the formulation scientists to study the pharmacological efficacy of prepared formulation. In addition, for dermal nanomedicines, the targeting potential is also an important parameter to manage the psoriasis. Hence, in the present work, cyclodextrin based nanostructures of babchi oil and its gel was fabricated and characterized comprehensively using photon correlation spectroscopy, transmission electron microscopy (TEM), Fourier transform infrared spectroscopy (FTIR), differential scanning calorimetry (DSC), viscosity studies, texture analysis and in vitro release studies. In vivo antipsoriatic efficacy of the babchi oil nanostructure gels was determined using mouse tail model. As per literature reports, it has been suggested that insufficient antioxidant defence system due to increased ROS (reactive oxygen species) generation and NO (nitric oxide) may be responsible for contribution of pathogenesis of psoriasis [Shen et al., 2008, Kadam et al., 2010, Oršolić et al., 2014]. Therefore, detailed biochemical estimation in terms of lipid peroxidation (LPO) by measurement of malondialdehyde (MDA) levels, nitric oxide (NO) production and estimation of vital enzymes involved in the antioxidation process including glutathione and superoxide dismutase (SOD) activity have been carried out to assess the oxidative stress and effect of treatment with babchi oil nanogels on these parameters have been determined. To the best of our knowledge, it is the first report on babchi oil being incorporated in cyclodextrin based nanogel and its detailed biochemical investigation in mouse tail psoriasis model.

\section{Materials and methods}

\subsection{Materials}

Babchi oil (BO) and $\beta$-cyclodextrins were supplied ex-gratis by Pukhraj Herbals, Mandsaur (India) and Jay-Chem Marketing, Mumbai (India), respectively. The crosslinker diphenyl carbonate (DPC), carbopol 934 and triethanolamine was procured from Sigma Aldrich, Milan (Italy), LOBA chemie Pvt. Ltd. Mumbai (India) and S D Fine-Chem Ltd., Mumbai (India), respectively. All other reagents and chemicals used were of analytical grade. Double distilled water was used throughout research. 


\subsection{Engineering of babchi oil nanostructures (BONS)}

Cyclodextrin-based nanostructures were engineered using previously reported method [Kumar et al., 2018, Rao et al., 2013, Rao et al., 2017]. Briefly, anhydrous $\beta-C D$ and diphenyl carbonate in molar ratio of 1:4 [Kumar et al., 2018] were heated to $95{ }^{\circ} \mathrm{C}$ on magnetic stirrer for $6 \mathrm{hrs}$. The mixture was cooled to ambient temperature and washed with water to remove $\beta$-CD (unreacted), followed by soxhlet extraction using acetone, to remove DPC (unreacted) and phenol. The obtained nanostructures were put at $40{ }^{\circ} \mathrm{C}$ in hot air oven for $2 \mathrm{hrs}$.

Babchi oil-loaded nanostructures (BONS) were prepared by freeze-drying technique [Swaminathan et al., 2013]. The fabricated nanostructures and babchi oil in ratio 1:4 were suspended in Milli-Q water $(50 \mathrm{ml})$ and was kept on magnetic stirrer for $24 \mathrm{hrs}$. The dispersion was centrifuged at $1500 \mathrm{rpm}$ for $10 \mathrm{~min}$ to separate unentrapped essential oil from the colloidal supernatant. The nanostructures were freeze dried in a Lyophilizer (Alpha 2-4 LD Plus CHRIST, Osterode, Germany). Typical freeze drying cycle consisted of $24 \mathrm{hrs}$ at temperature $\left(-81{ }^{\circ} \mathrm{C}\right)$ and operating pressure $(0.0010 \mathrm{mbar})$. The lyophilized powder was stored in desiccators [Anandam and Selvamuthukumar, 2014].

\subsection{Characterization and evaluation of $\mathrm{BO}$ nanostructures}

\subsubsection{Particle size, surface charge and morphology}

The sizes and polydispersity indices of BO nanostructures were examined using Malvern Zetasizer (Malvern Instruments Ltd, UK) using photo correlation spectroscopy. Zeta potential examinations were carried out using an additional electrode in the same instrument.

Transmission electron microscopy was employed to evaluate the topography of BONS. The samples were suspended in double distilled water. The sample was placed on carbon-coated copper grid and subsequently viewed under microscope at various magnifications using TEM (FEI Tecnai G 20 S-Twin, USA).

\subsubsection{Entrapment efficiency}

A weighed quantity $(5 \mathrm{mg}$ ) of BONS was suspended in DMSO followed by sonication for 10 min to release the essential oil form the nanostructure complex. The absorbance of the samples was recorded by UV spectrophotometer (Varian Cary -5000, Netherland) at $265 \mathrm{~nm}$ to calculate babchi oil content in nanostructures. The entrapment efficiency was calculated using the formula [Shende et al., 2012]:

Entrapment efficiency $(\%)=\frac{\text { Weig } \square \text { t of babchi oil in nanostructures }}{\text { Weig } \square \text { t of babchi oil fed initially }} \times 100$ 1

\subsubsection{Differential scanning calorimetry}

Differential scanning calorimetry of BO (Babchi oil), BONS (Babchi oil loaded nanostructures), BNS (Blank nanostructures), DPC (Diphenyl carbonate) and $\beta$-CD ( $\beta$ Cyclodextrin) was carried out using TA instruments, California (Discovery DSC25 series) 
equipped with a Refrigerated Cooling System 90 (RCS 90) and TRIOS software. The DSC instrument was graduated with indium for heat of enthalpy and melting point. A heating rate $\left(10{ }^{\circ} \mathrm{C} / \mathrm{min}\right)$ was applied in the $30-350{ }^{\circ} \mathrm{C}$ temperature range under nitrogen purge (50 $\mathrm{ml} / \mathrm{min}$ ). Standard aluminium empty pan (Perkin-Elmer) was used as reference standard.

\subsection{Incorporation of BO and BONS in Carbopol gel}

Carbopol 934 was used as the suitable gelling agent on the basis of its feel, ease of spreadability and compatibility with nanostructure dispersions. To this effect, BONS (equivalent to 5\%w/v BO) was uniformily mixed in Carbopol 934 solution (1\% w/v) and $\mathrm{pH}$ was maintained with triethanolamine resulting in nanogels [Mandawgade and Patravale, 2008]. In the similar way, plain Carbopol and BO loaded gel (5\%w/v) was also prepared for comparison.

\subsection{Evaluation of BONS loaded gels}

\subsubsection{Fourier Transform Infrared spectroscopy}

Pure babchi oil (BO), blank gel, BO gel $(5 \%$ w/v) as well as BONS gel $(5 \%$ w/v) were subjected to FTIR spectroscopic analysis by using a Perkin-Elmer system, Spectrum BX spectrophotometer, Waltham, USA. FTIR spectra were examined over the range 4,000 to 400 $\mathrm{cm}^{-1}$ with 16 scans and a resolution of $2.00 \mathrm{~cm}^{-1}$ [Johny et al., 2011, Gaikwad et al., 2012].

\subsubsection{Viscosity studies}

The viscosity studies on the gels (plain gel, BO gel and BONS gel) were performed using slightly modified method as reported previously [Sharma and Pathak, 2011] on a programmable Brookfield viscometer (model DV-E) at $25^{\circ} \mathrm{C}$. Spindle (No - 6) was lowered down perpendicularly into the fabricated gel placed in container taking care that the spindle does not touch the bottom of the container. The spindle was rotated at increasing speed from 0.5 to $100 \mathrm{rpm}$ and the viscometer readings were noted after $60 \mathrm{sec}$ when the level of gel gets stabilized. Results were plotted between viscosities versus shear rate.

\subsubsection{Spreadability}

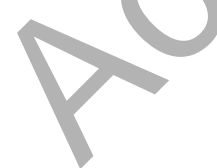

The spreadability of fabricated gels was examined using parallel plate method reported in previous studies [Marchiori et al., 2010, Doppalapudi et al., 2017]. Briefly, plain, BO and BONS gels ( $0.5 \mathrm{~g}$ each) were placed at the centre of glass slide and above it, another slide was positioned concentrically. Initial diameter of gel formulations was measured as diameter of circle, in which the gels were spread. Known weights (15, 20, 30, 50, 70, 100, 150 and 200 g) were positioned gradually on the upper plate at fixed time interval ( $1 \mathrm{~min})$. Subsequently, spreadability of gels was assessed on the basis of change in area on application of weights. 
Increase in spreading diameter was measured in horizontal and vertical axes after every addition of weight. Results were demonstrated in terms of the spreading area as per following equation:

$S=\pi d^{2} / 4$

where $\mathrm{S}$ represents spreading area $\left(\mathrm{cm}^{2}\right)$ and $\mathrm{d}$ represents the mean diameter $(\mathrm{cm})$ for each sample. Spreadability patterns were established by plotting the applied weights on $\mathrm{x}$-axis against spreading area on y-axis. These experiments were carried out in triplicate.

\subsubsection{Texture analysis}

The texture analysis was carried out using TA-XT2i Texture analyser with specific instrument setting. Penetration tests were performed using a cylindrical probe having diameter $25.0 \mathrm{~mm}(\mathrm{P} 25 / \mathrm{L} 5)$. The experiments were performed on plain gel, BO gel $(5 \% \mathrm{w} / \mathrm{v})$ and BONS gel $(5 \% \mathrm{w} / \mathrm{v})$. Furthermore, for an appropriate comparison, a plain carbopol (1\% w/v) gel was also evaluated. The gel sample formulations were formulated in cylindrical shape beakers; sample heights lies in the range $40.0 \pm 0.1 \mathrm{~mm}$ (having diameter $45.0 \pm 0.1$ $\mathrm{mm}$ ). At ambient temperature, the carbopol gel resistance for penetration and withdrawal of the cylindrical probe was measured. The pre-test speed, the test speed and the post-test speed were fixed at $1.0 \mathrm{~mm} / \mathrm{s}, 0.5 \mathrm{~mm} / \mathrm{s}$, and $10.0 \mathrm{~mm} / \mathrm{s}$, respectively, and $0.05 \mathrm{~N}$ trigger force was applied. Three replicates were performed for each gel sample. From penetration/withdrawal investigation, various parameters like work of cohesion representing the work required to conquer the internal bonds of the gel (the positive area upto maximum value under the forcetime curve), hardness representing the maximum positive force needed to achieve a given deformation (Fmax), the work of adhesion depicting the work required to pull the probe off from the gel (the negative area under the force-time curve) and springiness representing the rate at which a deformed sample reforms (elasticity), were derived [Coviello et al., 2015].

\subsection{In vitro release studies}

To counteract solubility challenges of babchi oil, a modified assay was adopted to check the actual release of babchi oil from the nanogel formulation. In brief, $1 \mathrm{gm}$ of BONS gel (equivalent to $5 \% \mathrm{w} / \mathrm{v}$ of babchi oil) was added in a dialysis bag (molecular weight: 12000 to $14000 \mathrm{Da}$, pore size: $2.4 \mathrm{~nm}$, Himedia). This dialysis bag was suspended in a $250 \mathrm{~mL}$ of PBS having $\mathrm{pH} 5.5$, at $37^{\circ} \mathrm{C}$ and rotated at $50 \mathrm{rpm}$. At pre-determined intervals, $5 \mathrm{ml}$ of PBS was collected and subsequently replaced with same amount of fresh dissolution media at same temperature. The collected samples were analysed using ultra-violet visible spectrophotometry. Further, the length of the dialysis bag was also kept same for all experiments in order to keep the surface area constant [Hua, 2014, Elmeshad et al., 2014].

\subsection{In vivo anti-psoriatic activity studies}

\subsubsection{Animal and maintenance}

Healthy female Swiss albino mice, weighing 20-25 g, aged four to six weeks were obtained from the Experimental Animal Facility, Guru Jambheshwar University of Science and 
Technology, Hisar, India. The mice were acclimatized for seven days prior to the treatments. The animals were housed in polypropylene cages under standard laboratory environment with $12 \mathrm{hrs}$ light and dark cycle at ambient temperature $\left(24-26{ }^{\circ} \mathrm{C}\right)$ and relative humidity (50$52 \%$ ). The animals had free access to food and water. Taking consideration that the research study strictly follows the guidelines for use and care of the laboratory animals, all the present experiments were carried out as per the protocol approved by the Guru Jambheshwar University of Science and Technology Animal Ethics Committee (Ref. letter no. IAEC/2016/26-34 dated on 05/12/2016).

\subsubsection{Experimental design and treatment}

Following seven days of acclimatization, the animals were randomized into six experimental groups (six animals each): (1) naive group, untreated animals; (2) sham-animals treated with blank Carbopol 1\%w/v gel; (3) animals treated with BO loaded gel (5\%w/y); (4) animals treated with BO loaded gel $(10 \% \mathrm{w} / \mathrm{v})$; (5) animals treated with BONS (equivalent to $5 \% \mathrm{w} / \mathrm{v}$ BO) loaded gel; (6) animal treated with CP loaded gel $(0.05 \% \mathrm{w} / \mathrm{v})$. The Plain BO was not chosen for evaluation owing to stability and ethical concerns [Kumar et al., 2018].

\subsubsection{Mouse tail model}

The anti-psoriatic potential of the prepared nanogels was investigated using a mouse tail method as per the protocol given in Fig. 1 [Bhatia et al., 2014]. The gel formulations (100 mg each) were applied using brush (once daily) to proximal part of tail for fourteen days. After application, the area was covered with sterile plastic film with the help of adhesive tape. The mice were humanely sacrificed $24 \mathrm{hrs}$ after the last application of gel formulations by giving anaesthesia (overdose of pentobarbitone sodium), and their tails were removed. Following this, the tail of animals were used for hematoxylin and eosin staining (for histopathological evaluation) and for the biochemical assays. The tail samples were stored in deep freezer (-80 $\left.{ }^{\circ} \mathrm{C}\right)$ till further processed.

For histological studies, the tail skin was dissected longitudinally with a blade and underlying cartilage was removed [Bhatia et al., 2009]. The resulting skin samples were stained with haematoxylin-eosin. The obtained samples were examined for epidermal thickness and also for the significant granular layer occurrence in scaly regions. Orthokeratosis induction was quantified by assessing granular layer (A) length and scale (B) length. Ten subsequent scales were measured for each skin section. Percent orthokeratosis was determined using Equation (3).

$\%$ Orthokeratosis $=(A / B) \times 100$

Drug activity (DA) represents the enhancement in percentage of orthokeratotic area per scale 30, which was calculated using Equation (4):

$D A=\frac{\text { Mean } O K \text { of Treated group-mean } O K \text { of control group }}{100-\text { mean } O K \text { of control group }} \times 100$ 
where OK is percent orthokeratosis [Bhatia et al., 2014].

\subsection{Biochemical assessments}

The tail samples stored in deep freezer $\left(-80^{\circ} \mathrm{C}\right)$ were taken out and processed for biochemical estimations. Tail skin were weighed and diluted in $1 / 10$ proportion with phosphate buffer saline (100 mmol/L, pH 7.4). The tissues were mechanically homogenized for $1 \mathrm{~min}$. The homogenate was centrifuged at $7000 \mathrm{rpm}$ for $15 \mathrm{~min}$. The resulting supernatant was subjected to biochemical estimation.

\subsubsection{Nitrite estimation}

Since, nitrite accumulation is an indicator of nitric oxide (NO) production, its accumulation was estimated using Greiss reagent as described in previous studies [Green et al., 1982]. To measure, nitrite levels, equal volumes $(0.5 \mathrm{ml})$ of supernatant and Greiss reagent were mixed at room temperature and incubated for $10 \mathrm{~min}$ in dark. Absorbance was examined at $540 \mathrm{~nm}$ through UV-Visible spectrophotometry. The nitrite concentration in the sample was calculated from sodium nitrite standard plot.

\subsubsection{Superoxide dismutase potential}

Superoxide dismutase potential was checked by method described earlier [Kono, 1978]. Briefly, the method is based on inhibition of nitro blue tetrazolium reduction by SOD, which was examined at $560 \mathrm{~nm}$ by spectrophotometry. Here, the reaction was initiated on addition of hydroxylamine hydrochloride to the nitro blue tetrazolium and sample mixture. Activity was revealed as units/mg protein, wherein one unit of SOD is defined as the quantity of enzyme causing 100 percent rate of reaction inhibition.

\subsubsection{Measurement of reduced glutathione}

Reduced glutathione estimation was determined as per method described [Ellman, 1959]. Briefly, $1.0 \mathrm{ml}$ of homogenate was mixed with $1.0 \mathrm{ml}$ of sulfosalicylic acid $(4 \% \mathrm{w} / \mathrm{v})$ and the reaction mixture was kept for $1 \mathrm{~h}$ at $4{ }^{\circ} \mathrm{C}$ for precipitation, instantly followed by centrifugation at $1,200 \times \mathrm{g}$ at $4{ }^{\circ} \mathrm{C}$ for $15 \mathrm{~min}$. The reaction mixture comprised $0.1 \mathrm{ml}$ of supernatant, $2.7 \mathrm{ml}$ of $0.1 \mathrm{mmol} / \mathrm{L}$ of phosphate buffer $(\mathrm{pH} 8.0)$, and $0.2 \mathrm{ml}$ of Ellman's reagent resulting in yellowish colour and absorbance was recorded instantly at $412 \mathrm{~nm}$ through UV-visible spectrophotometry. Results were expressed using the absorbance coefficient of chromophore $\left(1.36 \times 104 \mathrm{M}^{-1} / \mathrm{cm}\right)$ of GSH per mg protein.

\subsubsection{Lipid peroxidation measurement}

The quantitative estimation of lipid peroxidation was done as per previous method [Will, 1966]. The malondialdehyde content was determined by the reaction with thiobarbituric acid (TBA) at $532 \mathrm{~nm}$ through UV-visible spectrophotometry. The values were determined using the absorption coefficient of chromophore $\left(1.56 \times 105 \mathrm{M}^{-1} / \mathrm{cm}\right)$ of MDA-TBA complex. 


\subsubsection{Protein estimation}

Estimation of protein was carried out by biuret method taking bovine serum albumin as standard measuring absorbance at $540 \mathrm{~nm}$ through UV-Visible spectrophotometry [Gornall et al., 1949].

\subsection{Statistical analysis}

Graph Pad Prism (GraphPad Software Inc, San Diego, CA, USA) was subjected to all statistical investigations. The results were described as mean \pm SEM. The biochemical estimations were evaluated by one-way ANOVA followed by Tukey's post test. In all tests, $p<0.05$ was considered as criteria for statistical significance.

\section{Results and discussion}

Recent innovation in nanotechnology-based anti-psoriatic drug delivery shows a positive prospective in the psoriasis management therapy [Pradhan et al., 2013; Rahman et al., 2015]. However, regardless of so much work done on formulation development and preclinical reports, only very few clinical studies have been carried out to establish the clinical benefit of such novel nanoformulations. Although, topical treatment is the first line approach prescribed for patients with mild to moderate psoriasis [Katare et al., 2010]. But, most of the topical nanoformulations reported previously, were mainly composed of synthetic chemical lipids and surfactants which may be problematic in skin sensitive patients [Ali et al., 2008]. Therefore, surfactant free composition of nanostructures may prove as an added advantage of this disorder. Nanostructures have superior perspective like, to control structure of nanoparticles and, nature and size of pores by varying cross-linker: polymer molar ratio and degree of cross linking, which affect drug loading and its release [Trotta et al., 2012, Sherje et al., 2017, Prasad et al., 2018]. Further, babchi oil may play a significant role as an alternative if delivered efficiently in psoriasis management. In present investigation, BONS were successfully fabricated using $\beta$-cyclodextrin and diphenyl carbonate and loaded in Carbopol gel [Tejashri et al., 2013].

\subsection{Particle size, surface charge and morphology of developed nanostructures}

The particle size of BONS was observed as $360.9 \pm 19.55 \mathrm{~nm}$. Zeta potential (measure of surface charge) of BONS was found as $-16.0 \pm 4.15 \mathrm{mV}$ which may be due to higher repulsive forces and minimized tendency to aggregate. Low values of PDI $(0.311 \pm 0.059)$ with narrow range advocated the homogenous and stable nature of nanocolloidal formulation.

Using TEM, a single crystal of nanostructure can be focused and its definite crystalline geometry can be elucidated. As shown in TEM photographs (data not shown), the size of nanoformulation agreed well with zeta sizer findings. The topography using this microscopy showed that the nanostructures fabricated by melt method have uniform size distribution with crystalline and porous nature.

\subsection{Entrapment efficiency}


Entrapment efficiency of prepared BONS was found in the range between $93.05 \pm 0.28 \%$. Despite the lipophilic nature of the babchi oil, the developed nanostructures were able to offer a very high entrapment value [Aldawsari et al., 2015]. This could be due to firstly, crystalline nature of nanostructures formed by melt method; secondly, crosslinked network generating nanochannels along with $\beta-\mathrm{CD}$ nanocavities. The size of crosslinked network forming nanochannles depends on structural features of crosslinker and cyclodextrins [Tejashri et al., 2013, Olteanu, et al., 2014].

\subsection{Differential scanning calorimetry}

In DSC thermograms, when guest moieties get entrapped into pores of the nanostructures, their boiling, melting or sublimating points generally shifted to different temperature or disappear [Shende et al., 2015]. The endothermic peak at $80^{\circ} \mathrm{C}$ (enthalpy: $109.3 \mathrm{~J} / \mathrm{g}$ ) of DPC indicated its melting point and further, one more endothermic peak at $179{ }^{\circ} \mathrm{C}$ (enthalpy: 39.42 $\mathrm{J} / \mathrm{g}$ ) indicated its degradation (Fig.2a). In case of $\beta-\mathrm{CD}$, the first peak observed at $126^{\circ} \mathrm{C}$ (enthalpy: $328.26 \mathrm{~J} / \mathrm{g}$ ) was associated with release of water from $\beta$-CD [Abarca et al., 2016] and second peak at $301{ }^{\circ} \mathrm{C}$ (enthalpy: $179.94 \mathrm{~J} / \mathrm{g}$ ) was associated with melting point of $\beta$-CD (Fig.2a) [Sarfraz et al., 2017]. The endotherm in case of blank nanostructures showed a shift of $10{ }^{\circ} \mathrm{C}\left(116{ }^{\circ} \mathrm{C}\right.$; enthalpy: $\left.453.86 \mathrm{~J} / \mathrm{g}\right)$ and $5{ }^{\circ} \mathrm{C}\left(296{ }^{\circ} \mathrm{C}\right.$; enthalpy: $\left.73.65 \mathrm{~J} / \mathrm{g}\right)$ when compared to $\beta$-CD (Fig.2a). Babchi oil (BO) showed an endothermic peak at approx. $238^{\circ} \mathrm{C}$ (enthalpy: $16.65 \mathrm{~J} / \mathrm{g}$ ), which was found absent following its inclusion into nanostructures (BONS), confirming encapsulation of oil within the cyclodextrin nanostructures and offering protection to this essential oil (Fig. 2a) [Swaminathan et al., 2010]. BONS thermogram exhibits an endothermic peak at $302{ }^{\circ} \mathrm{C}$ (enthalpy: $4.88 \mathrm{~J} / \mathrm{g}$ ), which distinctly differs from the peak of blank nanostructures (BNS) (Fig. 2a). The lower phase transition temperature confirmed the occurrence of inclusion phenomenon between the nanostructure and BO (Fig. 2a). This is in corroboration with previous reports [Ansari et al., 2011, Dora et al., 2016].

\subsection{Incorporation of babchi oil and babchi oil loaded nanostructures in carbopol gel}

Carbopol 934, is a high molecular weight synthetic polymer containing carboxyl groups. In water, it swells upto1000 times its original volume to form a gel having $\mathrm{pH} 4.0$ to 6.0 [Guo et al., 2003]. Further, it is reported as non-irritant and non-sensitizing on long term use and is classified as Category 1 GRAS (Generally Recognized As Safe) agent and reported safe by Cosmetic Ingredient Review Expert Panel [Elder, 1982]. In gel form, it is an excellent medium for drug delivery. Owing to high molecular weight, it cannot permeate the skin, hence result in potential dermal action via depot formation of BONS, especially in case of psoriasis.

\subsection{Evaluation of $B O$ and $B O$ nanogel}

\subsubsection{Fourier Transform Infrared Spectroscopy}

Infrared spectra of blank gel, BO gel $(5 \% \mathrm{w} / \mathrm{v})$ and BONS gel $(5 \% \mathrm{w} / \mathrm{v})$ were used to study the compatibility between BO and polymeric gel. The FTIR spectrum of the babchi oil (BO) showed characteristic peaks at 3419, 2929, 1740, 1612, 1514, 1456, 1377, 1169 and $724 \mathrm{~cm}^{-1}$ (Fig.2b). 
The intensity of observed bands for babchi essential oil was found to be reduced in BO gel (prominent peaks: 2079, 1637, 1451, 1241, 1169,1093 and $676 \mathrm{~cm}^{-1}$; Fig.2b) and found further reduced in BONS gel (prominent peaks: 2066,1636, 1269, 1155, 1026 and $681 \mathrm{~cm}^{-1}$; Fig.2b), indicating encapsulation of BO in nanostructures [Swaminathan et al., 2010]. Further, FTIR of plain Carbopol gel showed IR bands at $3448 \mathrm{~cm}^{-1}, 2073 \mathrm{~cm}^{-1}, 1637 \mathrm{~cm}^{-1}$ and $675 \mathrm{~cm}^{-1}$ (Fig.2b). These bands were also present in BO gel as well as BONS gel, indicating absence of any interaction between essential oil and Carbopol gel and BONS and Carbopol gel (Fig. 2b) [Garala et al., 2013].

\subsubsection{Viscosity}

Rheological behavior of topical formulations has a significant impact on the spreadability of the formulation, contact time and its retention on the skin [Mortazavi and Tabandeh, 2005, Lee et al., 2009]. Therefore, viscosity profiles of the BO gel $(5 \% \mathrm{w} / \mathrm{v})$, plain Carbopol gel and BONS gel $(5 \% \mathrm{w} / \mathrm{v})$ were studied. A plot of the shear rate versus the measured viscosity of all the prepared gels showed decrease in viscosity with increasing shear rates (Fig. 3a) indicating pseudoplastic (Shear thinning) behaviour of the gel formulations. Such behaviour is a desirable feature for topical preparations, as they should remain thin during application and thick otherwise [Labib and Farid, 2015]. Further, it was observed that the viscosity of the BO gel was higher which could be due to highly viscous nature of the native babchi oil. As anticipated on encapsulation of BO into nanostructures the viscosity of the gel dropped and was equivalent to the plain Carbopol gel because of unavailability of the free oil in the gel [Batheja et al., 2011].

\subsubsection{Spreadability}

BO nanogels were fabricated by addition of BO nanostructures to Carbopol gel base which enhances BONS retention on the skin surface. Potency of a dermal delivery system depends on spreading behaviour of gel in an evenly manner to administer therapeutic dose. Further, this important property is important for appropriate dosage deportation to skin along with ease of application [Garg et al., 2002]. Hence, the spreadability of prepared gels was checked to verify the ease of application of the formulations. Fig. 3b depicts the spreadability behaviour of plain gel, BO gel $(5 \% \mathrm{w} / \mathrm{v})$ and BONS gel $(5 \% \mathrm{w} / \mathrm{v})$. Initial spreading area for plain gel and BO nanogel was $18.85 \pm 1.2$ and $17.64 \pm 0.15 \mathrm{~cm}^{2}$, respectively, whereas BO gel exhibited minimum spreading area $\left(16.13 \pm 0.89 \mathrm{~cm}^{2}\right)$ owing to high viscosity of the babchi oil. With $200 \mathrm{~g}$ weights, the spreading area was $122.88 \pm 0.65,129.47 \pm 0.81$ and $121.91 \pm 0.99 \mathrm{~cm}^{2}$ for plain gel, BONS gel and BO gel, respectively. No significant change in spreadability was detected between plain gel and BONS gel. However, spreadability profile of BO gel was observed less in comparison to plain gel and nanogel as indicated form spreading area-weight curve (Fig $\mathbf{3 b}$ ). Thus results are in line with viscosity measurements. Higher viscosity of BO gels could probably be responsible for its lower spreadability. However, inclusion of $\mathrm{BO}$ in cyclodextrin nanostructures resulted increase in its spreading area as compared to BO gel indicating that encapsulation of oil improved the capacity of the gel to spread over wider area and thus making it better suitable for topical delivery. 


\subsubsection{Texture analysis}

To carry out mechanical characterisation of plain gel, BO gel and BONS gel, texture analyser was used. The peak height of force-time plot provides hardness of gel formulations. It defines the resistance to compression demonstrating the ease of gel removal from container [Bansal et al., 2009].

The BO gel showed maximum hardness $(0.51 \pm 0.01 \mathrm{~N})$ followed by BONS gel $(0.25 \pm 0.01 \mathrm{~N})$ while blank gel $(0.24 \pm 0.07 \mathrm{~N})$ showed less hardness. The adhesiveness was found to be consistent with hardness of gels i.e. BONS gel $(-1.13 \pm 0.18 \mathrm{~N} \mathrm{sec})$ being more adhesive than BO gel $(-4.36 \pm 0.22 \mathrm{~N} \mathrm{sec})$ followed by Plain gel $(-4.48 \pm 0.22 \mathrm{~N} \mathrm{sec})$. Cohesiveness illustrates the structural recovery of gel following compression. The work of cohesion of gel was found in order: BONS gel $(0.84 \pm 0.035)>$ BO gel $(0.81 \pm 0.005)>$ plain gel $(0.76 \pm 0.034)$. The springiness of gel was found in order: BO gel $(0.90 \pm 0.036)<$ BONS gel $(0.91 \pm 0.056)<$ plain gel $(0.93 \pm 0.109)$.

As gel formulations fabricated for topical delivery should possess low hardness and high cohesiveness; our results for texture analysis of prepared BO nanogel were found suitable for topical application. Further, the higher adhesiveness is another feature desired for prolonged retention of formulation in skin, which is characteristic in BO nanogel (Table 1). Hence, BONS gel was found to possess all the attributes desired for dermal delivery.

\subsection{In vitro release analysis}

The in vitro release pattern of babchi oil from nanogel was compared with BO gel. The results indicated that approximately $99.91 \pm 0.52 \%$ babchi oil was released from the conventional BO gel within 4 hrs. In vitro release data of BONS gel showed that babchi oil release was slower in comparison to plain $\mathrm{BO}$ gel. Nanogels were found to exhibit sustained release of BO (Fig. 4a). Babchi oil released form BONS gel was approximately $34.21 \pm 0.62 \%$ in $24 \mathrm{hrs}$ signifying the role of nanostructures to cater sustained release of encapsulated essential oil over prolonged time [Aldawsari et al., 2015]. Incorporation of nanoformulation in hydrogel may serve as a local depot for sustained drug release and provide a rate limiting matrix barrier for modulating its drug release as observed in present investigation [Trotta et al., 2012]. These results were supported by FTIR studies of BONS gel. Similar results were obtained with econazole nitrate nanosponge fabricated using ethyl cellulose as polymer and subsequently loaded in hydrogel [Sharma et al., 2011]. BO release over long time period would help in averting periodic administration of oil improving the safety and patient compliance of long term therapy in psoriasis [Pradhan et al., 2013].

\subsection{In vivo anti-psoriatic activity}

Disrupted epidermal proliferation and keratinisation are the major aspects of psoriatic skin. Parakeratotic condition (hallmarks of psoriasis) is recognized in the adult mouse tail. The mouse tail is widely used animal model to examine the antipsoriatic potential of topical active moieties and their formulations with regards to the induction of orthokeratosis [Hofbauer et al., 1988, Sebok et al., 2000, Bhatia et al., 2009].

Naive and sham treatment did not create any considerable outcome, when compared together (data not shown). Therefore, only observations related to sham group have been discussed. 
Fig. 4b-f. portrays the histological characteristics of haematoxylin-eosin stained mouse tail skin sections after various treatments.

Group 2 (sham) depicts distinct signs of parakeratosis (Fig. 4b), a high density of keratinocytes with nucleus and reduction in granular layer was observed. Two weeks treatment with BONS gel $(5 \% \mathrm{w} / \mathrm{v})$ formulation (Fig.4e) resulted in marked histological variations in tail skin section as orthokeratotic stratum corneum spread longitudinally into the previously present parakeratotic condition. It was also observed, all the treatment groups revealed different orthokeratosis $(\mathrm{OK})$ scores as well as drug activity as represented in Table 2. The results indicated that BONS gel possessed remarkably enhanced $(p<0.05)$ antipsoriatic activity in comparison to sham (Fig.4b), CP gel (0.05\%w/v) (Fig.4f) and BO gel (5\%w/v) (Fig. 4c). Also, BONS gel revealed comparable antipsoriatic activity to BO gel $(10 \% \mathrm{w} / \mathrm{v})$ (Fig.4d) indicating that encapsulation of BO in cyclodextin nanostructures would lead to dose reduction by half as compared unencapsulated essential oil. The augumented action of the BONS gels (5\%w/v) (Fig.4e) could be attributed to its penetration of nanosize oil loaded nanosponge particles and targeted delivery to the epidermal layers of skin. These results are in consonance with improved therapeutic efficacy observed with topical nanosponges of lemongrass oil [Aldawsari et al., 2015]. Further, the results of current work are also in consonance with previous findings on anti-psoriatic activity of liposomal fusidic acid using the mouse tail model [Wadhwa et al., 2016].

\subsection{Biocompatibility and Safety}

In order to evaluate the safety of prepared BONS gels, visual and histopathological observations were assessed after their topical application. Visual observation showed no sign of skin irritation such as swelling and erythema after application of BONS gel. Further, histopathology images depicted no noticeable changes in tail skin of BONS treated groups in comparison with normal tail skin. The results advocate skin compatibility and safety of prepared nanosystem for topical delivery of babchi essential oil.

\subsection{Biochemical assessment}

Psoriasis is associated with proliferation and activation of keratinocytes and immune cells, hence, oxidative stress is likely to play a indispensable role in its pathogenesis. Oxidative stress involves imbalance between ROS and antioxidants resulting in molecular abnormalities and disruption of redox signalling. This redox imbalance plays a vital role in psoriasis pathogenesis. Mammalian cells possess an antioxidant defence mechanism, including GSH, SOD, catalase, perxiredoxins, thioredoxins, small molecules such as uric acid [Harrison, 2014]. Numerous studies revealed that significantly enhanced levels of oxidative stress markers along with decreased activity of antioxidant enzymes may participate much in pathogenesis of psoriasis [Panonnummal et al., 2017]. Hence in the present investigation, we explored the role of ROS in mouse tail model and the effect of babchi oil and its nanostructures on the oxidative stress markers. 


\subsubsection{Estimation of nitrite}

Nitric oxide (free radical) is produced by nitric oxide synthase mediated biotransformation. Generally, high levels of NO released by skin is known to play potential role in keratinocyte proliferation, a common symptom of psoriasis [Tekin et al., 2006]. As a vasodilator it is involved in numerous inflammatory reactions, causing edema, increased vascular permeability, erythema and increased cell infiltration, by enhancing local blood flow in the skin microcirculation [Rhodes et al., 2001, Kadam et al., 2010]. Hence, NO is a vital marker of inflammation, particularly in psoriasis. The production of nitric oxide is 10 -fold higher in nonlesional psoriatic skin and in the plaques [Weller and Ormerod, 1997]. In the present investigation, levels of NO followed the order: sham group (blank Carbopol gel) $>\mathrm{CP}$ gel $(0.05 \% \mathrm{w} / \mathrm{v})>\mathrm{BO}$ gel $(5 \% \mathrm{w} / \mathrm{v})>\mathrm{BO}$ gel $(10 \% \mathrm{w} / \mathrm{v})>$ BONS gel $(5 \% \mathrm{w} / \mathrm{v})$, respectively in mouse tail skin (Fig. 5a).

Further, NO levels were observed to be significantly lower in BONS gel group $(p<0.001)$ in comparison to $\mathrm{BO}$ gel $(5 \% \mathrm{w} / \mathrm{v}), \mathrm{CP}$ gel $(0.05 \% \mathrm{w} / \mathrm{v})$ and sham groups but were comparable to BO gel (10\%w/v) (Fig. 5a) clearly evidencing its superior efficacy as the effect is equivalent to conventional gel containing double the concentration of BO. These observations are in accordance with the histopathological results providing complimentary evidence for enhanced therapeutic activity of BONS gel.

\subsubsection{Measurement of SOD levels}

SOD, an endogenous enzymatic scavenger, acts as first line of protection against oxidative stress responsible for converting superoxide anion into $\mathrm{H}_{2} \mathrm{O}_{2}$ (hydrogen peroxide) [Briganti and Picardo, 2003, Kadam et al., 2010]. Reduced SOD levels might be associated to epidermal hyperproliferation, as ROS are likely to induce proliferation in various cells [Kobayashi et al., 1991, Iizuka and Takahashi, 1993]. Enhanced oxygen metabolism has been related with hyper proliferation owing to significant enzyme depletion inside the psoriatic skin. High superoxide anion $\left(\mathrm{O}_{2}\right)$ production along with reduced antioxidant activity would led to accumulation of $\mathrm{H}_{2} \mathrm{O}_{2}$, which is responsible for inhibition action of SOD function [lizuka and Takahashi, 1993, Górnicki and Gutsze, 2001]. Our results support the reduced SOD level in psoriatic skin as seen in control group, however on treatment with BONS gel the SOD levels were found to revert back. SOD levels were found to be significantly higher in the BONS gel $(5 \% \mathrm{w} / \mathrm{v})$ treated animals $(p<0.001)$ as compared to control, CP gel $(0.05 \% \mathrm{w} / \mathrm{v})$ and $\mathrm{BO}$ gel $(5 \% \mathrm{w} / \mathrm{v})$. However, the values were found comparable to BO gel $(10 \% \mathrm{w} / \mathrm{v})$ (Fig. 5b). These results are in corroboration with those obtained for NO levels.

\subsubsection{Estimation of Lipid peroxidation}

ROS influence oxidation of the polyunsaturated fatty acids in skin resulting in the formation of MDA [Carini et al., 2000], a biomarker of lipid peroxidation [Lykkesfeldt, 2007].

Enhanced LPO is known to induce inflammatory and immune responses, in addition to cell proliferation and activation of gene expression of cytokines. MDA tissue levels have been found to be higher in psoriatic lesions than in nonlesional tissues [Şikar et al., 2012]. Our results demonstrated that topical application of BONS gel resulted in significantly reduced 
MDA level in comparison to blank gel, CP gel $(0.05 \% \mathrm{w} / \mathrm{v})$ and $\mathrm{BO}$ gel $(5 \% \mathrm{w} / \mathrm{v})$ with $p$ value below 0.05 (Fig. 5c). Nevertheless, in comparison to BO gel $(10 \% \mathrm{w} / \mathrm{v})$, the MDA levels for BONS $(5 \% \mathrm{w} / \mathrm{v})$ nanogel were observed to be similar demonstrating efficacy of nanogel was equivalent to that observed with double the concentration of unencapsulated oil dinstinctingly illustrating the merit of nanostructure gel.

\subsubsection{Measurement of GSH levels}

GSH (a ubiquitous tripeptide thiol) is a vital extracellular and intracellular protective antioxidant [Carini et al., 2000]. It is highly polarisable and results in removal of radicals directly, owing to its property to neutralise excess production of ROS.This results in depeletion of its level. On topical treatment with BONS gel, GSH levels were found be enhanced $(p<0.05)$ when compared to plain gel, CP gel and BO gel (Fig. 5d) indicating reduced oxidative stress.

This biochemical estimation of MDA, GSH, SOD and nitrite levels provides an evidence for enhanced ROS production and poor antioxidant defences in psoriatic disease. However on treatment with BONS gel there was clear indication of reduction in oxidative stress and distinct induction of orthokeratosis. This was reflected by high GSH and SOD and reduced MDA and NO levels on treatment with BONS gels.

\section{Conclusion}

The present study advocates a novel cyclodextrin based nanocarrier gel of babchi oil for treatment of psoriasis. The BO encapsulated nanoparticles were successfully fabricated using diphenyl carbonate as crosslinker and incorporated into Carbopol 934 gel. Fabricated nanosponges resulted in high entrapment of BO. The nanogels displayed psuedoplastic behaviour with good spreadability and exhibited sustained release of BO warranting once dailt application, which, would be beneficial in improving patient compliance in chronic therapy of psoriasis. Two times enhanced anti-psoriatic activity was demonstrated in mousetail model, without any apparent skin irritation or symptoms like inflammation and erythema. Histological parameters along with biochemical assessment of oxidative stress biomarkers (enhanced level of SOD and GSH and decreased level of MDA and NO), provided evidence that BO nanoparticles gel plays a major role in management of ROS associated in psoriasis pathogenesis. In conclusion, topical babchi oil nanogel holds great promise in psoriasis treatment and warrants further clinical validation in humans for future commercial exploitation.

\section{Acknowledgements}

The authors are grateful to the coordinator, DST-FIST, Department of Pharmaceutical Sciences and Department of Food Technology, GJUS\&T, Hisar for carrying out, particle size and texture analysis, respectively. Authors would greatfully acknowledge to DST, New Delhi for financial assistance sanctioned to GJUS\&T, Hisar under PURSE Program No. [SR/PURSE/Phase2/40(G)]. The author Mr. Sunil Kumar, is thankful to Indian Council of 
Medical Research, New Delhi for providing Senior Research Fellowship [Letter No: 45/44/2018-Nan/BMS on dated 14/05/2018].

\section{Compliance with ethical standards}

Animal studies were performed in accordance with the Guidelines for Animal Experimentation of Guru Jambheshwar University of Science and Technology and approved by the Animal Ethics Committee of the institution (Ref. letter no. IAEC/2016/26-34 dated on 05/12/2016).

\section{Conflicts of interest}

The authors report no conflicts of interest in this work.

\section{References}

Abarca, R.L., Rodriguez, F.J., Guarda, A., Galotto, M.J. and Bruna, J.E., 2016. Characterization of beta-cyclodextrin inclusion complexes containing an essential oil component. Food Chem, 196, 968-975.

Aldawsari, H.M., Badr-Eldin, S.M., Labib, G.S., El-Kamel, A.H., 2015. Design and formulation of a topical hydrogel integrating lemongrass-loaded nanosponges with an enhanced antifungal effect: in vitro/in vivo evaluation. Int J Nanomedicine, 10, 893-902.

Ali, J., Akhtar, N., Sultana, Y., Baboota, S., Ahuja, A., 2008. Antipsoriatic microemulsion gel formulations for topical drug delivery of babchi oil (Psoralea corylifolia). Methods Find Exp Clin Pharmacol, 30(4), 277-285.

Anandam, S., Selvamuthukumar, S., 2014. Fabrication of cyclodextrin nanosponges for quercetin delivery: physicochemical characterization, photostability, and antioxidant effects. J Mater Sci, 49(23), 8140-8153.

Ansari, K.A., Vavia, P.R., Trotta, F., Cavalli, R., 2011. Cyclodextrin-based nanosponges for delivery of resveratrol: in vitro characterisation, stability, cytotoxicity and permeation study. AAPS Pharmscitech, 12(1), 279-286.

Bachir, Y.N., Medjkane, M., Benaoudj, F., Sahraoui, N., Hadj-ziane, A., 2017. Formulation of $\beta$-Cyclodextrin Nanosponges by Polycondensation Method: Application for Natural Drugs Delivery and Preservation. Journal of Materials, Processes and Environment, 5, 80-85.

Bakkali, F., Averbeck, S., Averbeck, D., Idaomar, M., 2008. Biological effects of essential oils-a review. Food Chem Toxicol, 46(2), 446-475. 
Bansal, K., Rawat, M.K., Jain, A., Rajput, A., Chaturvedi, T.P., Singh, S., 2009. Development of satranidazole mucoadhesive gel for the treatment of periodontitis. AAPS PharmSciTech, 10(3), 716-723.

Batheja, P., Sheihet, L., Kohn, J., Singer, A.J., Michniak-Kohn, B., 2011. Topical drug delivery by a polymeric nanosphere gel: formulation optimization and in vitro and in vivo skin distribution studies. J Control Release, 149(2), 159-67.

Baz, K., Cimen, M.Y., Kokturk, A., Yazici, A.C., Eskandari, G., Ikizoglu, G., Api, H., Atik, U., 2003. Oxidant/antioxidant status in patients with psoriasis. Yonsei Med J, 44(6), 987-990.

Bhatia, A., Raza, K., Singh, B., Katare, O.P., 2009. Phospholipid- based formulation with improved attributes of coal tar. J Cosmet Dermatol, 8(4), 282-288.

Bhatia, A., Singh, B., Wadhwa, S., Raza, K., Katare, O.P., 2014. Novel phospholipid-based topical formulations of tamoxifen: evaluation for antipsoriatic activity using mouse-tail model. Pharm Dev Technol, 19(2), 160-163.

Briganti, S., Picardo, M., 2003. Antioxidant activity, lipid peroxidation and skin diseases. What's new. J Eur Acad Dermatol Venereol, 17(6), 663-669.

Carini, M., Aldini, G., Piccone, M., Facino, R.M., 2000. Fluorescent probes as markers of oxidative stress in keratinocyte cell lines following UVB exposure. Farmaco, 55(8), 526-534.

Carrascosa, J.M., Pujol, R., Dauden, E., Hernanz-Hermosa, J.M., Bordas, X., Smandia, J.A., Ferrandiz, C., 2006. A prospective evaluation of the cost of psoriasis in Spain (EPIDERMA) project phase II). J Eur Acad Dermatol Venereol, 20, 840-845.

Chopra, B., Dhingra, A.K., Dhar, K.L., 2013. Psoralea corylifolia L.(Buguchi)-folklore to modern evidence. Fitoterapia, 90, 44-56.

Coviello, T., Trotta, A.M., Marianecci, C., Carafa, M., Di Marzio, L., Rinaldi, F., Di Meo, C., Alhaique, F., Matricardi, P., 2015. Gel-embedded niosomes: Preparation, characterization and release studies of a new system for topical drug delivery. Colloids Surf B Biointerfaces, 125, 291-299.

Dima, C., Cotârlet, M., Alexe, P., Dima, S., 2014. Microencapsulation of essential oil of pimento [Pimenta dioica (L) Merr.] by chitosan/k-carrageenan complex coacervation method. Innov Food Sci Emerg Technol, 22, 203-211.

Doppalapudi, S., Jain, A., Chopra, D.K., Khan, W., 2017. Psoralen loaded liposomal nanocarriers for improved skin penetration and efficacy of topical PUVA in psoriasis. Eur $J$ Pharm Sci, 96, 515-529.

Dora, C.P., Trotta, F., Kushwah, V., Devasari, N., Singh, C., Suresh, S., Jain, S., 2016. Potential of erlotinib cyclodextrin nanosponge complex to enhance solubility, dissolution rate, in vitro cytotoxicity and oral bioavailability. Carbohydr Polym, 137, 339-349. 
El Asbahani, A., Miladi, K., Badri, W., Sala, M., Addi, E.A., Casabianca, H., El Mousadik, A., Hartmann, D., Jilale, A., Renaud, F.N., Elaissari, A., 2015. Essential oils: from extraction to encapsulation. Int J Pharm, 483(1-2), 220-243.

Elder, R.L., 1982. Final Assessment Report of the Safety of Carbomers -934, -934P, -940, 941, and -962. J Amer College Toxicol,1(2), 109-141.

Ellman, G.L., 1959. Tissue sulfhydryl groups. Arch Biochem Biophys, 82, 70-77.

Elmeshad, A.N., Mortazavi, S.M., Mozafari, M.R., 2014. Formulation and characterization of nanoliposomal 5-fluorouracil for cancer nanotherapy. J Liposome Res, 24(1), 1-9.

Faiyazuddin, M., Akhtar, N., Akhter, J., Suri, S., Shakeel, F., Shafiq, S., Mustafa, G., 2010, Production, characterization, in vitro and ex vivo studies of babchi oil-encapsulated nanostructured solid lipid carriers produced by a hot aqueous titration method. Pharmazie, 65(5), 348-55.

Falcão, D.Q., Oliveira, A.P., Lima, B.G., Cardoso, A.C., Almeida, K.B., Santos, T.C., Nascimento, L.M., Desmarais, G.C., Sanches, P.S., Araújo, E.M., Mourão, S.C., 2018. Nanotechnology in phytotherapy: Current challenges of lipid-based nanocarriers for the delivery of natural products. In: Grumezescu AM, editor. Lipid Nanocarriers for Drug Targeting. William Andrew Applied Science Publishers, pp. 139-174.

Gaikwad, V.L., Yadav, V.D., Dhavale, R.P., Choudhari, P.B., Jadhav, S.D., 2012. Effect of carbopol 934 and 940 on fluconazole release from topical gel formulation: a factorial approach. Current Pharma Research, 2(2), 487-493.

Garala, K., Joshi, P., Shah, M., Ramkishan, A., Patel, J., 2013. Formulation and evaluation of periodontal in situ gel. Int J Pharm Investig, 3(1), 29-41.

Garg, A., Aggarwal, D., Garg, S., Singla, A.K., 2002. Spreading of semisolid formulations: an update. Pharm Technol, 26, 84-105.

Gornall, A.G., Bardawill, C.J., David, M.M., 1949. Determination of serum proteins by means of the biuret reaction. J Biol Chem, 177, 751-766.

Górnicki, A., Gutsze, A., 2001. Erythrocyte membrane fluidity changes in psoriasis: an EPR study. J Dermatol Sci,27(1), 27-30.

Green, L.C., Wagner, D.A., Glogowski, J., Skipper, P.L., Wishnok, J.S., Tannenbaum, S.R., 1982. Analysis of nitrate, nitrite, and [15N] nitrate in biological fluids. Anal Biochem, 126, 131-138.

Guo, J.H., 2003. Carbopol® Polymers for Pharmaceutical Drug Delivery Applications. Drug Deliv Technol, 3(6), 1-3.

Harrison, D.G., 2014. Basic science: pathophysiology: oxidative stress. J Am Soc Hypertens, $8,601-603$ 
Hofbauer, M., Dowd, P.M., Atkinson, J., Whitefield, M., Greaves, M.W., 1988. Evaluation of atherapeutic concentration of dithranol in the mouse-tail test. Br J Dermatol, 118(1), 85-89.

Hua, S., 2014. Comparison of in vitro dialysis release methods of loperamide-encapsulated liposomal gel for topical drug delivery. Int J Nanomedicine, 9, 735-744.

Iizuka, H., Takahashi, H., 1993. Psoriasis, involucrin, and protein kinase C. Int Journal Dermatol, 32(5), 333-338.

Johny, J.M., Kulandhaivel, M., Palaniswamy, M., Jose, R., 2011. Evaluation and FTIR Qualitative Analysis and of Gel Based Hand Wash Using Camellia sinensis (Green Tea) and Myristica fragrans (Nutmeg) Formulation. Int J Pharm Biol Arch, 2(4), 1202-1208.

Kadam, D.P., Suryakar, A.N., Ankush, R.D., Kadam, C.Y., Deshpande, K.H., 2010. Role of oxidative stress in various stages of psoriasis. Indian J Clin Biochem, 25(4), 388-392.

Katare, O.P., Raza, K., Singh, B., Dogra, S., 2010. Novel drug delivery systems in topical treatment of psoriasis: rigors and vigors. Indian J Dermatol Venereol Leprol, 76(6), 612-621.

Khushboo, P.S., Jadhav, V.M., Kadam, V.J., Sathe, N.S., 2010. Psoralea corylifolia Linn."Kushtanashini". Pharmacogn Rev, 4(7), 69-76.

Kobayashi, T., Matsumoto, M., Iizuka, H., Suzuki, K., Taniguchi, N., 1991. Superoxide dismutase in psoriasis, squamous cell carcinoma and basal cell epithelioma: an immunohistochemical study. Br J Dermatol, 124(6), 555-559.

Kono, Y., Generation of superoxide radical during autoxidation ofhydroxylamine and an assay for superoxide dismutase. Arch Biochem Biophys, 186, 189-195.

Kumar, S., Pooja, Trotta, F., Rao, R., 2018. Encapsulation of Babchi Oil in cyclodextrinBased Nanosponges: Physicochemical Characterization, Photodegradation and in Vitro Cytotoxicity Studies. Pharmaceutics, 10(4), 169.

Kumar, S., Rao, R., 2016. Psoralen: A promising boon in topical manifestations. IJP, 3(9), 375-383.

Labib, G.S., Farid, R.M., 2015. Osteogenic effect of locally applied Pentoxyfilline gel: in vitro and in vivo evaluations. Drug Deliv, 22(8), 1094-1102.

Lahlou, M., 2013. The success of natural products in drug discovery. Pharmacol Pharm, 4(3A), 17-31.

Langan, S.M., Seminara, N.M., Shin, D.B., Troxel, A.B., Kimmel, S.E., Mehta, N.N., Margolis, D.J., Gelfand, J.M., 2012. Prevalence of metabolic syndrome in patients with psoriasis: a population-based study in the United Kingdom. J Invest Dermatol, 132(3), 556562.

Lee, C.H., Moturi, V., Lee, Y., 2009. Thixotropic property in pharmaceutical formulations. $J$ Control Release, 136(2), 88-98. 
Leelarungrayub, J., Manorsoi, J., Manorsoi, A., 2017. Anti-inflammatory activity of niosomes entrapped with Plai oil (Zingiber cassumunar Roxb.) by therapeutic ultrasound in a rat model. Int J Nanomedicine, 12, 2469-2476.

Low, W.L., Martin, C., Hill, D.J., Kenward, M.A., 2013. Antimicrobial efficacy of liposome- encapsulated silver ions and tea tree oil against Pseudomonas aeruginosa, Staphylococcus aureus and Candida albicans. Lett Appl Microbiol, 57(1), 33-39.

Lykkesfeldt, J., 2007. Malondialdehyde as biomarker of oxidative damage to lipids caused by smoking. Clinica chimica acta, 380(1-2), 50-58.

Mandawgade, S.D., Patravale, V.B., 2008. Development of SLNs from natural lipids: application to topical delivery of tretinoin. Int J Pharm, 363(1-2), 132-138.

Marchiori, M.L., Lubini, G., Dalla Nora, G., Friedrich, R.B., Fontana, M.C., Ourique, A.F., Bastos, M.O., Rigo, L.A., Silva, C.B., Tedesco, S.B., Beck, R.C., 2010. Hydrogel containing dexamethasone-loaded nanocapsules for cutaneous administration: preparation, characterization, and in vitro drug release study. Drug Dev Ind Pharm, 36(8), 962-971.

Marwaha, T.K., Bhise, K.S., 2014. Formulation design and evaluation of anti-inflammatory activity of commiphora mukul loaded emulgel. J Res Educ Indian Med,20(2), 75-87.

Menter, A., Griffiths, C.E., 2007. Current and future management of psoriasis. The Lancet, 370(9583), 272-284.

Moghimipour, E., Ramezani, Z., Handali, S., 2013. Solid lipid nanoparticles as a delivery system for Zataria multiflora essential oil: formulation and characterization. Curr Drug Deliv, 10(2), 151-157.

Mortazavi, S.A., Tabandeh, H., 2005. The influence of various silicones on the rheological parameters of AZG containing silicone-based gels. Iran J Pharm Res, 4(4), 205-211.

Nahr, F.K., Ghanbarzadeh, B., Hamishehkar, H., Kafil, H.S., 2018. Food grade nanostructured lipid carrier for cardamom essential oil: Preparation, characterization and antimicrobial activity. J Funct Foods, 40, 1-8.

Olteanu, A.A., Aramă, C.C., Radu, C., Mihăescu, C., Monciu, C.M., 2014. Effect of $\beta$ cyclodextrins based nanosponges on the solubility of lipophilic pharmacological active substances (repaglinide). J Incl Phenom Macrocycl Chem, 80(1-2), 17-24.

Oršolić, N., Skurić, J., Đikić, D., Stanić, G., 2014. Inhibitory effect of a propolis on Di-nPropyl Disulfide or n-Hexyl salycilate-induced skin irritation, oxidative stress and inflammatory responses in mice. Fitoterapia, 93, 18-30.

Panonnummal, R., Jayakumar, R., Sabitha, M., 2017. Comparative anti-psoriatic efficacy studies of clobetasol loaded chitin nanogel and marketed cream. Eur J Pharm Sci, 96, 193206. 
Paul, C., Gallini, A., Maza, A., Montaudié, H., Sbidian, E., Aractingi, S., Aubin, F., Bachelez, H., Cribier, B., Joly, P., Jullien, D., 2011. Evidence- based recommendations on conventional systemic treatments in psoriasis: systematic review and expert opinion of a panel of dermatologists. J Eur Acad Dermatol Venereol, 25(s2), 2-11.

Pople, P.V., Singh, K.K., 2011. Development and evaluation of colloidal modified nanolipid carrier: application to topical delivery of tacrolimus. Eur J Pharm Biopharm, 79(1), 82-94.

Pople, P.V., Singh, K.K., 2013. Development and evaluation of colloidal modified nanolipid carrier: Application to topical delivery of tacrolimus, Part II-In vivo assessment, drug targeting, efficacy, and safety in treatment for atopic dermatitis. Eur J Pharm Biopharm, 84(1), 72-83.

Pradhan, M., Singh, D., Singh, M.R., 2013. Novel colloidal carriers for psoriasis: current issues, mechanistic insight and novel delivery approaches. J Control Release, 170(3), 380395.

Prasad, M., Lambe, U.P., Brar, B., Shah, I., Manimegalai, J., Ranjan, K., Rao, R., Kumar, S., Mahant, S., Khurana, S.K., Iqbal, H.M., 2018. Nanotherapeutics: An insight into healthcare and multi-dimensional applications in medical sector of the modern world. Biomed Pharmacother, 97, 1521-1537.

Rahman, M., Akhter, S., Ahmad, J., Ahmad, M.Z., Beg, S., Ahmad, F.J., 2015. Nanomedicine-based drug targeting for psoriasis: potentials and emerging trends in nanoscale pharmacotherapy. Expert Opin Drug Deliv, 12(4), 635-652.

Rao, M., Bajaj, A., Khole, I., Munjapara, G., Trotta, F., 2013. In vitro and in vivo evaluation of $\beta$-cyclodextrin-based nanosponges of telmisartan. J Incl Phenom Macrocycl Chem, 77(14), 135-145.

Rao, M.R.P., Shirsath, C., 2017. Enhancement of Bioavailability of Non-nucleoside Reverse Transciptase Inhibitor Using Nanosponges. AAPS PharmSciTech, 18(5), 1728-1738.

Raut, G., Wairkar, S., 2018, Management of psoriasis with nutraceuticals: An update. Complement Ther Clin Pract, 31, 25-30.

Rhodes, L.E., Belgi, G., Parslew, R., McLoughlin, L., Clough, G.F., Friedmann, P.S., 2001. Ultraviolet-B-induced erythema is mediated by nitric oxide and prostaglandin E2 in combination. Jinvest Dermatol, 117(4), 880-885.

Roberts, M.S., Mohammed, Y., Pastore, M.N., Namjoshi, S., Yousef, S., Alinaghi, A., Haridass, I.N., Abd, E., Leite-Silva, V.R., Benson, H.A., Grice, J.E., 2017. Topical and cutaneous delivery using nanosystems. J Control Release, 247, 86-105.

Sampada, S., Singh, K.K., 2015. Nanophytomedicine - Current and Future Perspectives. In: Singh, B., Singh, K.K., Rekhi, G.S. editors. NanoBioMedicine Vol. 2: Nanopharmaceuticals, Studium Press LLC, pp 568. 
Sapino, S., Carlotti, M.E., Cavalli, R., Ugazio, E., Berlier, G., Gastaldi, L., Morel, S., 2013. Photochemical and antioxidant properties of gamma-oryzanol in beta-cyclodextrin-based nanosponges. J Incl Phenom Macrocycl Chem, 75(1-2), 69-76.

Sarfraz, R.M., Ahmad, M., Mahmood, A., Akram, M.R., Abrar, A., 2017. Development of $\beta$ cyclodextrin-based hydrogel microparticles for solubility enhancement of rosuvastatin: an in vitro and in vivo evaluation. Drug Des, Devel Ther, 11, 3083.

Sebok, B., Bonnekon, B., Kerenyi, M., Gollnick, H., 2000. Tazarotene induces epidermal cell differentiation in the mouse tail test used as an animal model for psoriasis. Skin Pharmacol Appl Skin Physiol, 13(5), 285-291.

Shailajan, S., Menon, S., Singh, A., Mhatre, M., Sayed, N., Joshi, H., Tiwari, B., 2012. Estimation of psoralen from herbal formulations containing Psoralea corylifolia using the RP-HPLC-DAD method and its application to a pharmacokinetic study. Int J Green Pharm, 6(3), 217-223.

Sharma, R., Pathak, K., 2011. Polymeric nanosponges as an alternative carrier for improved retention of econazole nitrate onto the skin through topical hydrogel formulation. Pharm Dev Technol, 16, 367-376.

Sharma, R., Walker, R.B., Pathak, K., 2011. Evaluation of the kinetics and mechanism of drug release from econazole nitrate nanosponge loaded carbapol hydrogel. Indian Journal of Pharmaceutical Education and Research, 45(1), 25-31.

Shen, T., Zhu, Q.X., Yang, S., Wu, C.H., Zhang, H.F., Zhou, C.F., Zhang, X.J., 2008. Trichloroethylene induced cutaneous irritation in BALB/c hairless mice: histopathological changes and oxidative damage. Toxicol, 248(2), 113-120.

Shende, P.K., Gaud, R.S., Bakal, R., Patil, D., 2015. Effect of inclusion complexation of meloxicam with $\beta$-cyclodextrin-and $\beta$-cyclodextrin-based nanosponges on solubility, in vitro release and stability studies. Colloids Surf B Biointerfaces, 136, 105-110.

Shende, P.K., Trotta, F., Gaud, R.S., Deshmukh, K., Cavalli, R., Biasizzo, M., 2012. Influence of different techniques on formulation and comparative characterization of inclusion complexes of ASA with $\beta$-cyclodextrin and inclusion complexes of ASA with PMDA cross-linked $\beta$-cyclodextrin nanosponges. J Incl Phenom Macrocycl Chem, 74(1-4), 447-454.

Sherje, A.P., Dravyakar, B.R., Kadam, D., Jadhav, M., 2017. Cyclodextrin-based nanosponges: a critical review. Carbohydr Polym, 173, 37-49.

Şikar, A., Özdoğan, H.K., Bayramgürler, D., Çekmen, M.B., Bilen, N., Kıran, R., 2012. Nitric oxide and malondialdehyde levels in plasma and tissue of psoriasis patients. $J$ Eur Acad Dermatol Venereol, 26(7), 833-837.

Suresh, P.K., Singh, P., Saraf, S., 2013. Novel topical drug carriers as a tool for treatment of psoriasis: progress and advances. Afr J Pharm Pharmacol, 7(5), 138-147. 
Swaminathan, S., Pastero, L., Serpe, L., Trotta, F., Vavia, P., Aquilano, D., Trotta, M., Zara, G., Cavalli, R., 2010. Cyclodextrin-based nanosponges encapsulating camptothecin: physicochemical characterization, stability and cytotoxicity. Eur J Pharm Biopharm, 74(2), 193-201.

Swaminathan, S., Vavia, P.R., Trotta, F., Cavalli, R., Tumbiolo, S., Bertinetti, L., Coluccia, S., 2013. Structural evidence of differential forms of nanosponges of beta-cyclodextrin and its effect on solubilization of a model drug. J Incl Phenom Macrocycl Chem, 76(1-2), 201211.

Tejashri, G., Amrita, B., Darshana, J., 2013. Cyclodextrin based nanosponges for pharmaceutical use: A review. Acta Pharm, 63(3), 335-358.

Tekin, N.S., Ilter, N., Sancak, B., Ozden, M.G., Gurer, M.A., 2006. Nitric oxide levels in patients with psoriasis treated with methotrexate. Mediators Inflamm, 2006(3), 16043.

Trotta, F., Zanetti, M., Cavalli, R., 2012. Cyclodextrin-based nanosponges as drug carriers. Beilstein J Org Chem, 8, 2091-2099.

Wadhwa, G., Kumar, S., Chhabra, L., Mahant, S., Rao, R., 2017. Essential oil-cyclodextrin complexes: an updated review. J Incl Phenom Macrocycl Chem, 89(1-2), 39-58.

Wadhwa, G., Kumar, S., Mittal, V., Rao, R., 2019. Encapsulation of babchi essential oil into microsponges: Physicochemical properties, cytotoxic evaluation and anti-microbial activity. $J$ Food Drug Anal, 27(1), 60-70.

Wadhwa, S., Singh, B., Sharma, G., Raza, K., Katare, O.P., 2016. Liposomal fusidic acid as a potential delivery system: a new paradigm in the treatment of chronic plaque psoriasis. Drug Deliv, 23(4), 1204-1213.

Weller, R., Ormerod, A., 1997. Increased expression of inducihie nitric oxide (NO) synthase. Br J Dermatol, 136(1), 136-137.

Wills, E., 1966. Mechanisms of lipid peroxide formation in animal tissues. Biochem J, 99, 667-676.

World Health Organization. Global report on psoriasis. 2016. WHO Library Cataloguing-inPublication Data. 2016. 
Figure captions

Figure 1 Experimental protocol. MDA malondialdehyde.

Figure 2 a) Differential scanning calorimetry (DSC) thermograms of BO (Babchi oil), BONS (Babchi oil loaded nanostructures), BNS (Blank nanostructures), DPC (Diphenyl carbonate) and $\beta$-CD ( $\beta$-cyclodextrin); b) Fourier transform infrared (FTIR) spectra of BO (Babchi Oil), Blank gel (Blank Carbopol gel), BO gel (Babchi oil loaded gel) and BONS gel (Babchi oil nanostructures loaded gel).

Figure 3 Evaluation of Carbopol gels (a) Shear rate vs measured viscosity curves of Carbopol gels and (b) Graphical representation of the spreadability of fabricated gels determined by parallel plate method (mean \pm standard deviation; $\mathrm{N}=3$ ).

Figure 4a Cumulative babchi oil released from BO gel and BONS gel (mean \pm standard deviation, $\mathrm{N}=3$ ). Histopathological evaluation of mice tail skin after various treatments (b) Control (c)BO gel 5\%w/v (d) BO gel 10\%w/v and (e) BONS gel 5\%w/v (f) CP gel $0.05 \%$ w/v. Calibration bar $=100 \mu \mathrm{m}$

Figure 5 The mean levels of NO expression (a), sodium dismutase (b), MDA (c) and reduced glutathione (d) in the tail skin tissue of mice treated topically from different experiment groups. $\mathrm{N}=6$ each group. Data are in mean \pm SD. Data were analyzed by one way ANOVA followed by Tukey's test for multiple comparisons. BO: Babchi oil gel, BONS: Babchi oil loaded nanostructures gel, CP: Clobetasol propionate gel.

For Figure a: ${ }^{\mathrm{a}} \mathrm{p}<0.001$ versus control, ${ }^{\mathrm{b}} \mathrm{p}<0.001$ versus $\mathrm{BO} 5 \% \mathrm{w} / \mathrm{v}$ gel For Figure b: ${ }^{a} \mathrm{p}<0.001$ versus control, ${ }^{\mathrm{b}} \mathrm{p}<0.001$ versus BO 5\%w/v gel For Figure c: ${ }^{\mathrm{a}} \mathrm{p}<0.05$ versus control, ${ }^{\mathrm{b}} \mathrm{p}<0.001$ versus control, ${ }^{\mathrm{c}} \mathrm{p}<0.01$ versus BO 5\%w/v gel For Figure d: ${ }^{\mathrm{a}} \mathrm{p}<0.05$ versus control, ${ }^{\mathrm{b}} \mathrm{p}<0.001$ versus control, ${ }^{\mathrm{c}} \mathrm{p}<0.05$ versus BO 5\%w/v gel, ${ }^{\mathrm{d}} \mathrm{p}<0.001$ versus BO $5 \% \mathrm{w} / \mathrm{v}$ gel, ${ }^{\mathrm{e}} \mathrm{p}<0.01$ versus BO $10 \% \mathrm{w} / \mathrm{v}$ gel 


\begin{tabular}{|l|l|l|l|l|l|l|l|l|l|l|l|l|l|l|}
\hline Day & Day & Day & Day & Day & Day & $\begin{array}{l}\text { Day } \\
\text { 00 }\end{array}$ & $\begin{array}{l}\text { Day } \\
\text { D2 }\end{array}$ & $\begin{array}{l}\text { Day } \\
03\end{array}$ & $\begin{array}{l}\text { Day } \\
04\end{array}$ & $\begin{array}{l}\text { Day } \\
05\end{array}$ & $\begin{array}{l}\text { Day } \\
06\end{array}$ & $\begin{array}{l}\text { Day } \\
12\end{array}$ & $\begin{array}{l}\text { Day } \\
13\end{array}$ & $\begin{array}{l}\text { Day } \\
14\end{array}$ \\
\hline
\end{tabular}

14 days drug or nanoformulation treatment

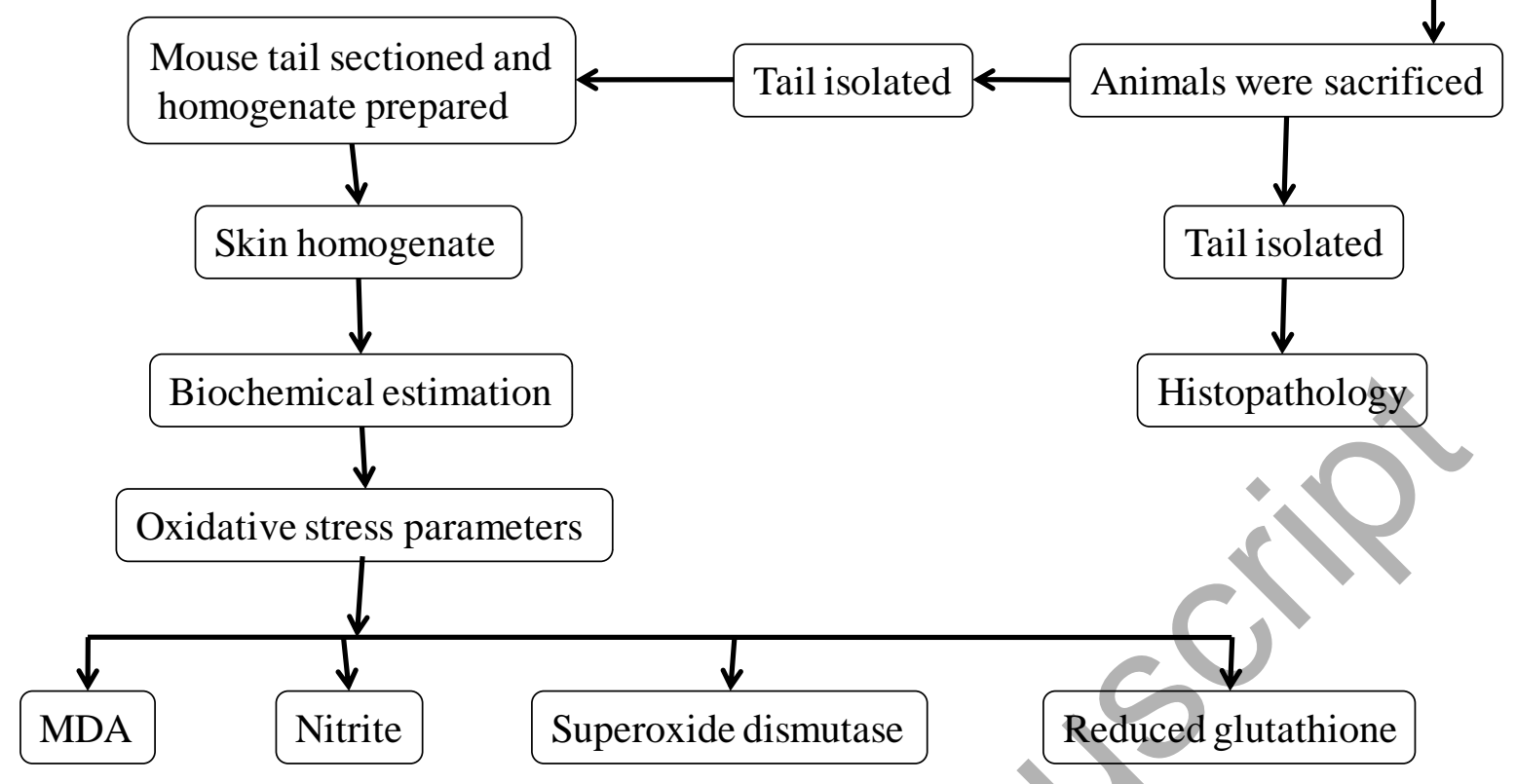

Figure 1 Experimental protocol. MDA malondialdehyde.
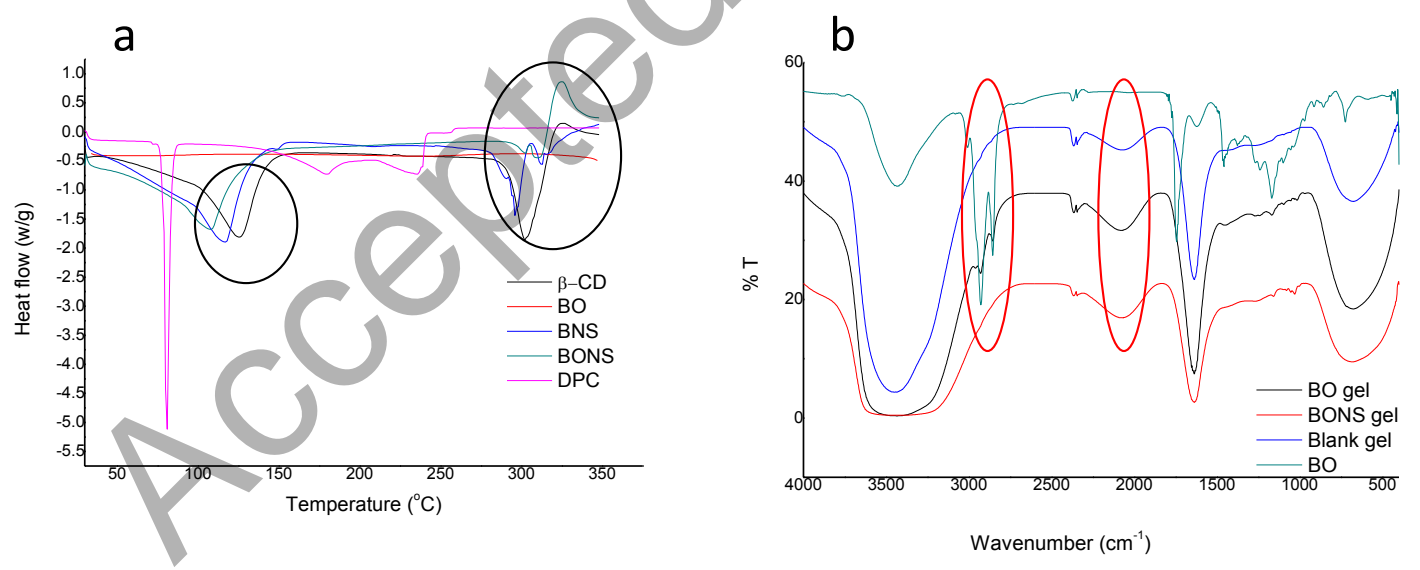

Figure 2 a) Differential scanning calorimetry (DSC) thermograms of BO (Babchi oil), BONS (Babchi oil loaded nanostructures), BNS (Blank nanostructures), DPC (Diphenyl carbonate) and $\beta$-CD ( $\beta$-cyclodextrin); b) Fourier transform infrared (FTIR) spectra of BO (Babchi Oil), Blank gel (Blank Carbopol gel), BO gel (Babchi oil loaded gel) and BONS gel (Babchi oil nanostructures loaded gel). 

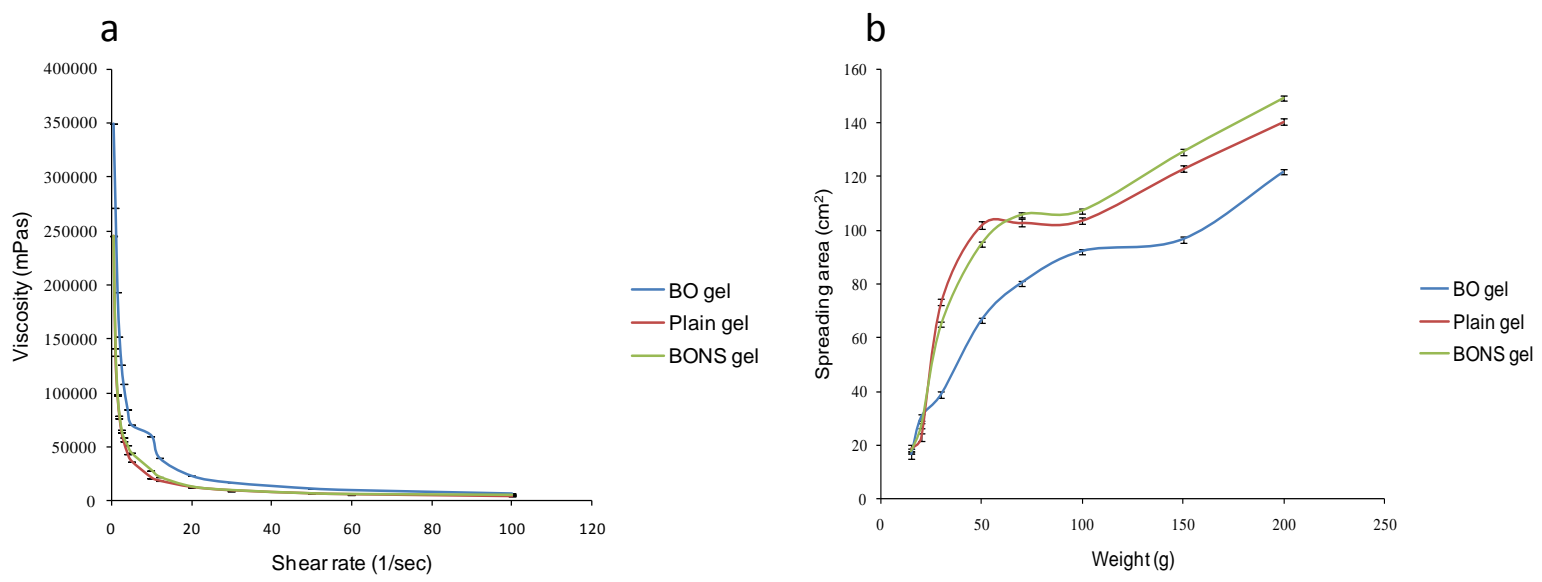

Figure 3 Evaluation of Carbopol gels (a) Shear rate vs measured viscosity curves of Carbopol gels and (b) Graphical representation of the spreadability of fabricated gels determined by parallel plate method (mean \pm standard deviation; $\mathrm{N}=3$ ).
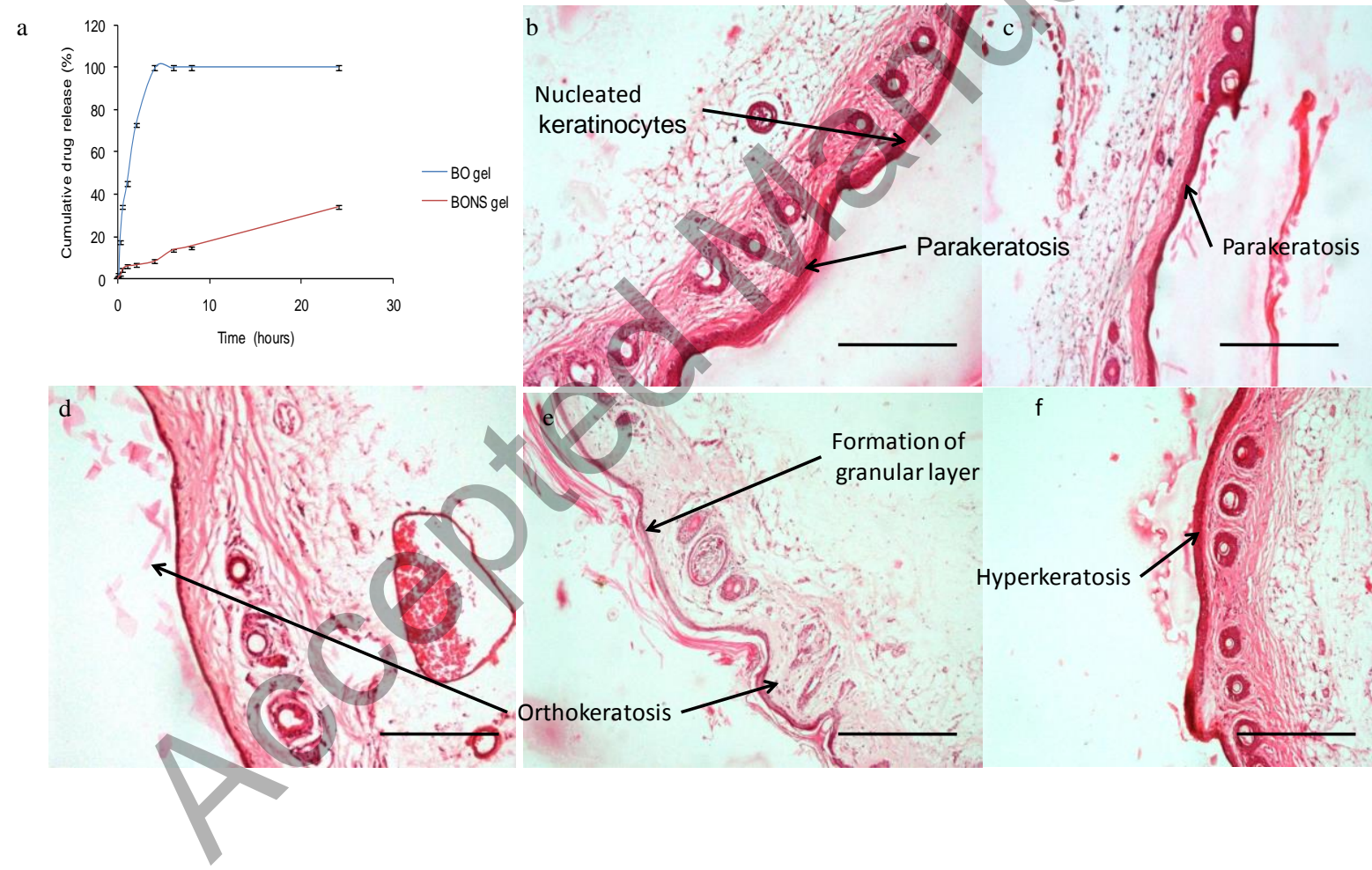

Figure 4a Cumulative babchi oil released from BO gel and BONS gel (mean \pm standard deviation, $\mathrm{N}=3$ ).

Histopathological evaluation of mice tail skin after various treatments (b) Control (c)BO gel 5\%w/v (d) BO gel $10 \% \mathrm{w} / \mathrm{v}$ and (e) BONS gel 5\%w/v (f) CP gel $0.05 \% \mathrm{w} / \mathrm{v}$. Calibration bar $=100 \mu \mathrm{m}$ 
a
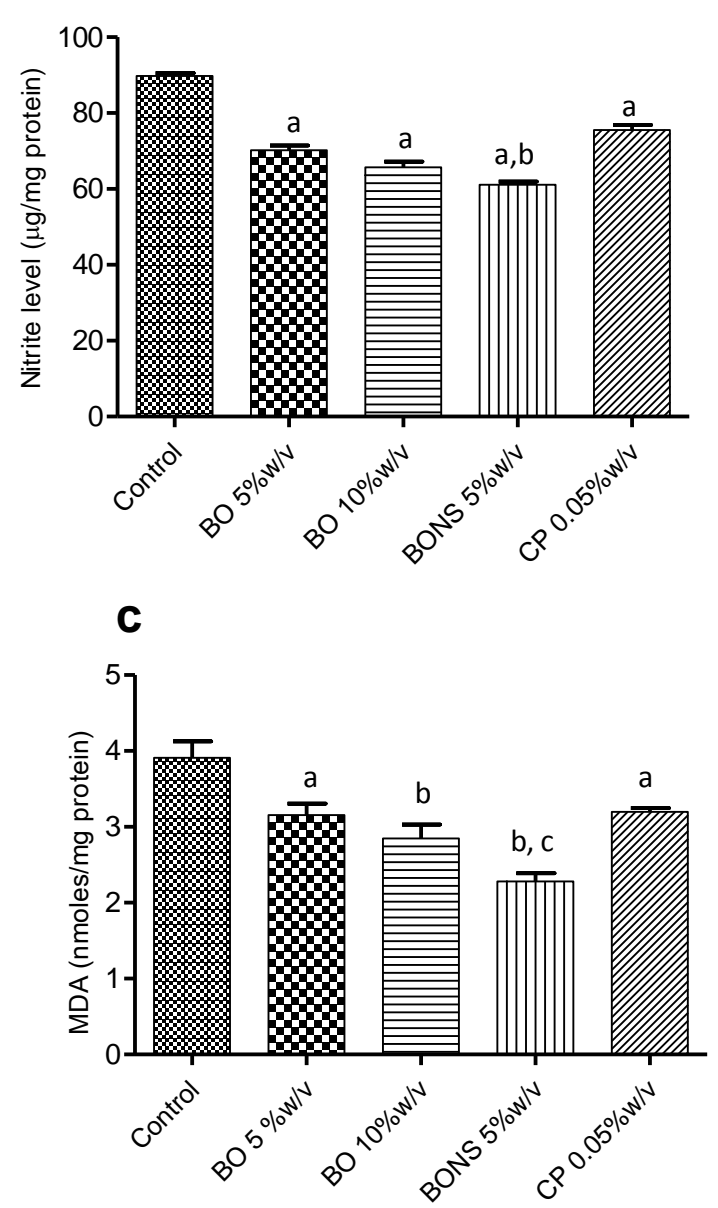

\section{b}
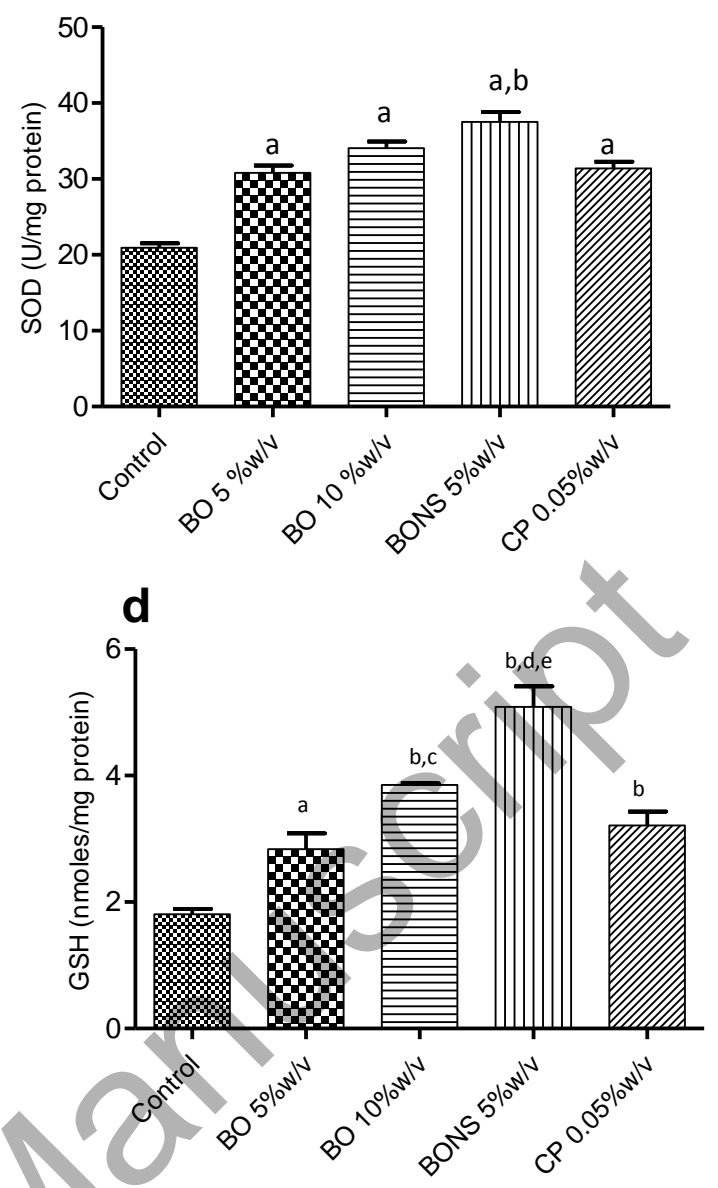

Figure 5 The mean levels of NO expression (a), sodium dismutase (b), MDA (c) and reduced glutathione (d) in the tail skin tissue of mice treated topically from different experiment groups. $\mathrm{N}=6$ each group. Data are in mean $\pm \mathrm{SD}$. Data were analyzed by one way ANOVA followed by Tukey's test for multiple comparisons. BO: Babchi oil gel, BONS: Babchi oil loaded nanostructures gel, CP: Clobetasol propionate gel.

For Figure a: ${ }^{\mathrm{a}} \mathrm{p}<0.001$ versus control, ${ }^{\mathrm{b}} \mathrm{p}<0.001$ versus BO 5\%w/v gel For Figure b: ${ }^{\mathrm{a}} \mathrm{p}<0.001$ versus control, ${ }^{\mathrm{b}} \mathrm{p}<0.001$ versus BO 5\%w/v gel For Figure c: ${ }^{\mathrm{a}} \mathrm{p}<0.05$ versus control, ${ }^{\mathrm{b}} \mathrm{p}<0.001$ versus control, ${ }^{\mathrm{c}} \mathrm{p}<0.01$ versus BO 5\%w/v gel For Figure d: ${ }^{\mathrm{a}} \mathrm{p}<0.05$ versus control, ${ }^{\mathrm{b}} \mathrm{p}<0.001$ versus control, ${ }^{\mathrm{c}} \mathrm{p}<0.05$ versus BO 5\%w/v gel, ${ }^{\mathrm{d}} \mathrm{p}<0.001$ versus BO $5 \% \mathrm{w} / \mathrm{v}$ gel, ${ }^{e} \mathrm{p}<0.01$ versus BO $10 \% \mathrm{w} / \mathrm{v}$ gel 


\section{Table captions}

Table 1 Hardness, work of cohesion and adhesion, and springiness for the different tested samples, recorded at room temperature.

\begin{tabular}{lllll}
\hline Sample & $\begin{array}{l}\text { Hardness }(\mathbf{N}) \\
\mathbf{\pm S D}\end{array}$ & $\begin{array}{l}\text { Work of adhesion } \\
(\mathbf{N ~ s e c}) \pm \text { SD }\end{array}$ & $\begin{array}{l}\text { Work of cohesion } \\
\mathbf{\pm S D}\end{array}$ & Springiness $\mathbf{\pm S D}$ \\
\hline Plain gel & $0.24 \pm 0.07$ & $-4.48 \pm 0.22$ & $0.76 \pm 0.034$ & $0.93 \pm 0.109$ \\
BO gel $(\mathbf{5 \%}$ w/v) & $0.51 \pm 0.01$ & $-4.36 \pm 0.22$ & $0.81 \pm 0.005$ & $0.90 \pm 0.035$ \\
BONS gel $(\mathbf{5 \%} / \mathbf{w})$ & $0.25 \pm 0.01$ & $-1.13 \pm 0.18$ & $0.84 \pm 0.035$ & $0.91 \pm 0.056$ \\
\hline
\end{tabular}

Table 2 Change in epidermal thickness, percent orthokeratosis and percent drug activity of different gel formulations.

\begin{tabular}{|c|c|c|c|c|}
\hline Sr. No. & Formulation & $\begin{array}{c}\text { Relative epidermal } \\
\text { thickness } \pm \text { SD }\end{array}$ & $\begin{array}{c}\% \text { Orthokeratosis } \\
\pm \text { SD }\end{array}$ & $\begin{array}{c}\text { Drug activity } \\
\pm \text { SD }\end{array}$ \\
\hline 1. & Plain gel & $100 \pm 0.00$ & $47.28 \pm 1.32$ & $00.00 \pm 0.00$ \\
\hline 2. & $\mathrm{BO}$ gel $(5 \% \mathrm{w} / \mathrm{v})$ & $56.73 \pm 4.43^{\mathrm{a}, \mathrm{c}}$ & $60.59 \pm 1.58^{a}$ & $25.17 \pm 4.82^{\mathrm{a}}$ \\
\hline 3. & BO gel $(10 \% \mathrm{w} / \mathrm{v})$ & $42.32 \pm 5.81^{\mathrm{a}, \mathrm{b}}$ & $67.67 \pm 0.91^{\mathrm{a}, \mathrm{b}}$ & $38.62 \pm 3.21^{\mathrm{a}, \mathrm{b}}$ \\
\hline 4. & BONS gel $(5 \% \mathrm{w} / \mathrm{v})$ & $30.44 \pm 5.86^{\mathrm{a}, \mathrm{b}, \mathrm{c}}$ & $73.66 \pm 2.20^{\mathrm{a}, \mathrm{b}, \mathrm{c}}$ & $50.06 \pm 3.58^{\mathrm{a}, \mathrm{b}, \mathrm{c}}$ \\
\hline 5. & $\mathrm{CP}$ gel $(0.05 \% \mathrm{w} / \mathrm{v})$ & $69.52 \pm 4.50^{\mathrm{a}}$ & $58.11 \pm 1.01^{\mathrm{a}}$ & $26.64 \pm 2.61^{\mathrm{a}}$ \\
\hline
\end{tabular}

